\title{
Effect of Brochure Concerning to Early Postpartum Hemorrhage on Enhancing Nurses' Knowledge and Practices
}

\author{
Amal Mahmoud Dawood ${ }^{1}$, Kamilia Ragab Abou Shabana ${ }^{2}$, \\ Sahar Mossa Soliman ${ }^{2}$, Amal Talaat El Sharkawy ${ }^{3}$ \\ ${ }^{1}$ Assist. Lecture, M.Sc. of Maternity and gynecological Nursing-Faculty of Nursing Alexandria University, ${ }^{2}$ Prof. of \\ Maternal and Gynecological Nursing-Faculty of Nursing Ain Shams University, ${ }^{3}$ Assistant Prof. of Maternal and \\ Gynecological Nursing-Faculty of Nursing Ain Shams University
}

\begin{abstract}
Aim: To investigate the effect of brochure concerning to early postpartum hemorrhage on enhancing nurses' knowledge, practices and satisfaction.

Setting: At obstetric departments in Damanhur teaching hospital at Beheira Governorate. Study Design: A Quasi- experimental (an interventional study) pre and posttest. Sample type: Purposive sample. Sample size: 40 nurse Tools: Three tools 1) A structured interviewing questionnaire. 2) An observational checklist. And 3) Nurses' satisfaction tool.

Results: The result of the present study findings was highly significant improvement in total knowledge and total practical skills among the studied sample pre intervention compared to immediate and eight weeks post intervention. $\mathrm{P}=<0.01$ Additionally $83 \%$ among studied sample satisfied with the advanced knowledge included in the brochure.

Conclusion: The present study findings concluded that a significant improvement among studied sample' knowledge and practices post intervention. Also the majority among the studied sample were satisfied the implemented brochure.
\end{abstract}

Recommendations: Nursing standards, protocols and guideline must be designed to enhance nurses' knowledge, practices and satisfaction.

Keywords: Improving Nurses' Practices, Early Postpartum Hemorrhage.

\section{Introduction}

A brochure is an informative paper document that can be folded into a template, pamphlet or leaflet. Brochures are promotional documents, primarily used to introduce services for decreasing maternal, fetal and neonatalmorbidity and mortality from early Postpartum hemorrhage ( $\mathrm{PPH})$. Early postpartum hemorrhage is defined as blood loses over $500 \mathrm{ml}$ or more from the genital tract within the first 24 hours post the vaginal birth of neonate. Incidence of early postpartum hemorrhage is accounting for a quarter of all maternal deaths. In total there are 14 million cases of hemorrhage occurred every year in association with pregnancy and childbirth. According to world health statistics 2015, every day, approximately 830 women died from preventable causes related to childbirth. Among 830 deaths occurs daily, 250 women are died due to earlypostpartum hemorrhage $(\mathrm{PPH}){ }^{(10)}$ Causes of early postpartum hemorrhage can be explained by the 4T's theory: Tone - Uterine a tony $(70-90 \%)$, Retained tissue that was estimated for $6-10 \%$ of all cases, Trauma leading to $20 \%$ of all cases and coagulation defects that accounting for $1 \%$ of all early PPH mortality. ${ }^{(1)}$ Furthermore,immediate complications of early postpartum hemorrhage are disseminated intravascular coagulation (DIC), Hypovolemic shock, severe anemia, clotting disorders, acute renal failure, sepsis, wound infection, pneumonia, venous thrombosis or embolism and acute lung injury, damage to the anterior pituitary gland may result in delay or failure of lactation as well as secondary infertility and 
Less commonly myocardial ischemia ${ }^{(9)}$. Moreover,the successful management of early PPH must be focused on three components,medical therapy, Mechanical procedures and surgical therap. ${ }^{(4)}$ Nurses play a multidisciplinary role as a direct care provider, health educator and counselor, as a manager and as a researcher for patients with early postpartum hemorrhage.

Significance of the Study: In Egypt, especially in rural areas, postpartum hemorrhage ( $\mathrm{PPH})$ is still one of the main causes responsible for maternal morbidity and mortality. That's it still needs a radical solution. Moreover, According to Damanhur teaching hospital statistics 2017, approximately, the incidence of early postpartum hemorrhage (PPH) was $12.5 \%$.Furthermore; early postpartum hemorrhage (PPH) was the nursing concern because she plays a multidisciplinary role as a care giver for early detection, screening and referring patients with early postpartum hemorrhage to minimize maternal and fetal morbidity and mortality. No previous studies implemented brochure for early postpartum hemorrhage at Damanhur teaching hospital.

Aim of the Study: To investigate the effect of brochure concerning to early postpartum hemorrhage on enhancing nurses' knowledge, practices and satisfaction.

Research Hypothesis: Nurses who received brochure about early postpartum hemorrhage has shown better knowledge, practices and satisfaction more than those who didn't participated.

\section{Subject and Method}

Setting: The study was conducted at obstetric departments in Damanhur teaching hospital at Beheira Governorate.

Study Design: A Quasi- experimental (an intervention study) pre and post test

\section{Sampling:}

(a) Size: All nurses (44nurses) who were working at obstetric departments and accepted to participate in study, at previously mentioned study setting.

(b) Type: purposive sample was included.

\section{Exclusion Criteria:}

1. Age less than 18 year and more than 40years.

2. Working as an administrator nurse.

3. Education with Bachelor of Nursing.
Tools of Data Collection: Three tools were used by the researcherafter reviewing the advanced related literature. All tools of data collection implemented pre intervention then immediate and eight weeks post intervention but satisfaction tool was implemented eight weeks post intervention only.

First Tool:Structured interviewing questionnaire schedule which included two parts:The first part: assessed nurse's general characteristics (age, level of education, qualification, area of residence, years of experience and attendance of training programs).

The second part: assessed nurses' knowledge regarding early postpartum hemorrhage. Which involved 14 multiple choice questions.

The knowledge scoring system was2 score for correct answer and one score for incorrect answer. The total knowledge correct score was $(\geq 60 \%)$ while, the total knowledge for the incorrect score was $(<60 \%)$.

The second tool was an observational checklist: To assess nurse's practices while providing patient's care every 15 minute for the first four hrs with early postpartum hemorrhage. Scoring system for anan observational checklist wasevaluated as 2 score for correct practice andone score for incorrect practice. The total correct practice was scored as $\geq 60 \%$ while incorrect practice total scored as $<60 \%$.

The third tool was "Nurse Satisfaction tool" adopted from (Sayed, et al., 2015), and included two parts.

The first part: Assessed nurses〉 satisfaction regarding an instructional supportive guideline which involved eight statements. Upon which nurses respond as satisfied, dissatisfied and uncertainly satisfied.

The second part: Assessed barriers that prevent nurses to comply with implemented guidelinewhile providing patient> care which involved six statements. This was evaluated eight weeks post intervention.

Aninstructional Supportive brochurewas designed by researcher according to nurses learning needs pre intervention based upon advanced related literature.

Content validity and reliability: All tools of data collections were developed and sent to three specialized university Prof. according to their comments, modification were considered. 
Pilot Study: A pilot study was conducted for $10 \%$ from total number of sample to evaluate the simplicity and clarity of tools that was used in the study.

Field work or Operational design: The study was implemented through three phases included the preparatory, implemented and evaluation phase.

Phase one (preparatory Phase): The researcher was reviewed the current advanced national and international literature related to the study topic, then prepared tools for data collection and designed an instructional supportive brochure. Finally, pilot study was conducted

Phase two (implementation phase): Firstly, the researcher was interviewed three nurses/day according to sequence of their attendance in hospital registration book and explain the aim of the study to obtain their oral consent. Interview was conducted in a separate place to maintain confidentiality of the study.(duration of each interview $20 \mathrm{~min}$ ).

- Secondly, nurse>s practices were assessed using an observational checklist, while they are providing patients care with early postpartum hemorrhage.

- Each day, two nurses' practices were assessed from $9 \mathrm{Am}$ to $9 \mathrm{pm}$.
- After the completion of assessment of nurses' practices. An instructional supportive brochure was implemented through 10 sessions for each program for six months duration of each session was 20 minute, number of participant (6) nurse/ each session. Three sessions for theoretical learning and seven sessions were implemented for practical training.

- Method of teaching were (groupdiscussion, lectures, brain storming, demonstration and bed side teaching).

- Media were (lab-top computer, figures, flipe chart as well as audiovisual aids (data show presentation) and role play.

Phase three (evaluation Phase): This phase was utilized to evaluate the effect ofimplementedbrochureon enhancing nurses> knowledge and practices among patients with early postpartum hemorrhage.All tools of data collection were used pre intervention then immediately and 8 weeks post- intervention but the nurses' satisfaction tool was used only eight weeks post intervention.Nurses' practice was assessed on three patients three times then the mean was obtained for statiscally analysis.

\section{Results}

Table (1): Frequency distribution according to the studied sample total correct and incorrect knowledge related to early postpartum hemorrhage pre, immediate and eight weeks post intervention. $(n=40)$.

\begin{tabular}{|c|c|c|c|c|c|c|c|c|}
\hline \multirow{2}{*}{ Items } & \multicolumn{2}{|c|}{$\begin{array}{c}\text { Pre-instructional } \\
\text { supportive guideline }\end{array}$} & \multicolumn{2}{|c|}{$\begin{array}{l}\text { Immediate Post-instructional } \\
\text { supportive guideline }\end{array}$} & \multicolumn{2}{|c|}{$\begin{array}{l}\text { Eight weeks post instructional } \\
\text { supportive guideline }\end{array}$} & \multicolumn{2}{|c|}{ Friedman test } \\
\hline & $\mathbf{N}$ & $\%$ & $\mathbf{N}$ & $\%$ & $\mathbf{N}$ & $\%$ & $\mathrm{X}^{2} \%$ & p-value $\mathbf{N}$ \\
\hline Correct & 10 & 25 & 32 & 80 & 28 & 70 & \multirow{2}{*}{34.19} & \multirow{2}{*}{$.000 * *$} \\
\hline Incorrect & 30 & 75 & 8 & 20 & 12 & 30 & & \\
\hline
\end{tabular}

Table (2): Frequency distribution according to the studied sample total correct and incorrect practices related to early postpartum hemorrhage pre, immediate and eight weeks post intervention. $(n=40)$.

\begin{tabular}{|l|c|c|c|c|c|c|c|c|}
\hline \multirow{2}{*}{ Items } & \multicolumn{2}{|c|}{$\begin{array}{c}\text { Pre-instructional } \\
\text { supportive guideline }\end{array}$} & \multicolumn{2}{|c|}{$\begin{array}{c}\text { Immediate Post- } \\
\text { instructional } \\
\text { supportive guideline }\end{array}$} & \multicolumn{2}{|c|}{$\begin{array}{c}\text { Eight weeks post } \\
\text { instructional } \\
\text { supportive guideline }\end{array}$} & \multicolumn{2}{c|}{ Friedman test } \\
\cline { 2 - 8 } & $\mathbf{N}$ & $\mathbf{\%}$ & $\mathbf{N}$ & $\%$ & $\mathbf{N}$ & $\%$ & $\mathbf{X}^{2} \%$ & p-value N \\
\hline Correctpractical skills & 12 & 30 & 30 & 75 & 25 & 62.5 & \multirow{2}{*}{32.74} & $.000 * *$ \\
\hline Incorrect practical skills & 28 & 70 & 10 & 25 & 15 & 37.5 & & \\
\hline
\end{tabular}


Table (3): Frequency distribution according to the studied sample satisfaction eight weeks post intervention regarding the implemented guideline $(n=40)$.

\begin{tabular}{|c|c|c|c|c|c|c|}
\hline \multirow{2}{*}{ Items } & \multicolumn{2}{|c|}{ Satisfied } & \multicolumn{2}{|c|}{ Uncertainly Satisfied } & \multicolumn{2}{|c|}{ Unsatisfied } \\
\hline & $\mathbf{N}$ & $\%$ & $\mathbf{N}$ & $\%$ & $\mathbf{N}$ & $\%$ \\
\hline The guideline enhances nurses' practices. & 33 & 82.5 & 4 & 10 & 3 & 7.5 \\
\hline $\begin{array}{l}\text { Guideline language was clear and easily to be understood and } \\
\text { effective. }\end{array}$ & 32 & 80 & 6 & 15 & 2 & 5 \\
\hline The aim of the guideline was matched with its content. & 28 & 70 & 7 & 17.5 & 5 & 12.5 \\
\hline $\begin{array}{l}\text { The place of implementing guideline was comfortable with } \\
\text { good ventilation and lighting. }\end{array}$ & 31 & 77.5 & 8 & 20 & 3 & 7.5 \\
\hline Number of participant was suitable to the place of training. & 27 & 67.5 & 9 & 22.5 & 4 & 10 \\
\hline $\begin{array}{l}\text { The implemented guideline contribute to the development and } \\
\text { updating nursing knowledge regarding early PPH. }\end{array}$ & 30 & 75 & 8 & 20 & 2 & 5 \\
\hline Session time did not interfere with hospital working schedule. & 22 & 55 & 12 & 30 & 6 & 15 \\
\hline $\begin{array}{l}\text { Guideline was recommended to be replicated for another nurses } \\
\text { and another setting in the future. }\end{array}$ & 28 & 70 & 8 & 20 & 4 & 10 \\
\hline
\end{tabular}

Table (4): Correlation between total knowledge and practices among studied sample related to early postpartum hemorrhage at pre, immediate post and eight weeks post intervention. $(n=40)$

\begin{tabular}{|l|c|c|c|c|c|c|}
\hline \multirow{2}{*}{ Item } & \multicolumn{2}{|c|}{$\begin{array}{c}\text { Total practice at } \\
\text { pre-guideline. }\end{array}$} & \multicolumn{2}{|c|}{$\begin{array}{c}\text { Total practice at immediate } \\
\text { post - guideline. }\end{array}$} & \multicolumn{2}{c|}{$\begin{array}{c}\text { Total practice at eight } \\
\text { weeks post - guideline. }\end{array}$} \\
\cline { 2 - 7 } & $\mathbf{r}$ & P- value & $\mathbf{r}$ & P-value & $\mathbf{r}$ & P- value \\
\hline Total knowledge at pre- guideline. & 0.452 & $.000^{* *}$ & & & & \\
\hline Total knowledge at immediate post- guideline. & & & 0.462 & $.000^{* *}$ & & \\
\hline Total knowledge at eight weeks post - guideline. & & & & & 0.458 & $.000^{* *}$ \\
\hline
\end{tabular}

$(*)$ Statistically significant at $\mathrm{p}<0.05$

\section{Discussion}

The present study was aimed toinvestigate the effect of brochure concerning to early postpartum hemorrhage on enhancing nurses' knowledge, practices and satisfaction. This aim was significantly approved within the framework of the present study's research hypothesis which was nurses who received brochure about early postpartum hemorrhage has shown better knowledge, practice and satisfaction more than those who didn't participated. Concerning nurses' knowledge related to early postpartum hemorrhage. The present study research findings revealed that, there was a highly significant improvement of nursess knowledge post intervention compared to pre intervention. The present study findings was agreed with ${ }^{(6)}$ who found that there was significantly improvement of nurses' knowledge post intervention compared to pre intervention because he found that educational programs (both booklet and education) for the prevention and management of early PPH led to significant improvements in the knowledge of obstetric nurses.

Also, the present study was agreed with $^{(2)}$ who illustrated that there was a highly significant improvement among nurses regarding total knowledge score post intervention compared to pre intervention. Furthermore, a study was conducted by ${ }^{(3)}$. Who pointed out that, there was highly statistically significant difference between pre and post intervention among nurses' knowledge regarding early PPH. This similarity may be due to their sample was from Egyptian community and the same culture.

Concerning nurses' practices, the present study findings had revealed that a significant improvement in nurses' practices immediately and eight weeks post intervention.This result is in line with ${ }^{(4)}$ whofoundthat 
nurses had incorrect practice at pre intervention phase and highly improved immediately and three months post intervention. Additionally, this result is in the same line with the present study ${ }^{\left({ }^{8}\right)}$ who reported that a significant improvement in nurses' practices regarding early $\mathrm{PPH}$ after implementation of brochure.

These findings point out the successful effect of implementation of brochure to maternity nurses as method for continuous updating and improved their knowledge and skills to promote and improve their competences. Thus, there is a clear role in continuing professional development activities of nurses which have ultimate reflection on improving patient's care outcome.

Finally, it was observed from present study findings that highly significant relations between nurses 'knowledge and their practices. This because nurses 'knowledge was considered the base for their practices. This result was supported by (5), who had found highly significant association between obstetric nurses' knowledge and their practices. As well ${ }^{(7)}$, who reported that positive statistically significant correlation between the studied subjects' knowledge score and their practices.

The present study findings had pointed out our attention toward the importance of implemented brochure because it was illustrated from the present study findings that there was a highly retention of study sample knowledge and practices eight weeks post intervention. This is due to the effectiveness and practicability of the implemented brochure. The majority nurses among studied sample were satisfied with the implemented brochure the majority had reported that the brochure language was easily understood and the aim was matched with its content. Also, the place of implemented brochure was comfortable with good ventilation and lighting.

Additionally,the implemented brochure contributes to the development and updating with advanced knowledge regarding early PPH and enhance nurses' practices. Moreover, the majority among studied sample was suggested to replicate the present study brochure to other nurses in another setting in the future to enhance nurses' knowledge and practices and the majority among nurses was highly satisfied with implementation brochure.

\section{Conclusion}

It was observed in the present study findings a highly significant on enhancing nurse' knowledge, practices and satisfaction post intervention compared to pre intervention. Additionally, the majority among the studied sample was highly satisfied with the application of nursing brochure.

\section{Recommendations:}

- Hospital administrator must direct their attention toward relieving nurses from administrative work and to devote their time for nurses' activities only.

- Design and implement monitoring system to evaluate nurses' practices at obstetric department continuously.

- Designing nursing standards, protocols and brochure for all nurses at obstetric department.

- The present study, implemented brochure was recommended to replicate at another setting and on larger sample.

- Periodically planned pre service, in-service and on job training programs related to early post-partum hemorrhage.

- Further study investigates health team immediate intervention related to early Postpartum Hemorrhage at obstetric department.

Ethical Clearance: Taken from the Scientific Research Committee at the Faculty of Nursing, Ain Shams University.

\section{Source of Funding: Self}

\section{Conflict of Interest: Nil}

\section{Reference}

1. Donati, S; Basevi, V; Balestreri D, et al. Linee Guida Nazionali: Emorragia postpartum: come prevenirla, come curarla. Available at http://www. iss.it/binary/moma/cont/LGEPPcorrige.pdf.2018

2. Faiza, A;N. Knowledge and Practice of Nurse Midwives Regarding Management and Prevention of Postpartum Hemorrhage in Three Selected Teaching Hospitals-Khartoum State-Sudan. Ind J of Appl Res. 2015; 5(4): 634-8.

3. Hassan, S; M.E. A study of the effect of nursing intervention program on reduction of postpartum hemorrhage, Faculty of Nursing Menoufiya 
University Doctorate Degree In Nursing Science, Department of Maternal And Newborn Health Nursing.2016; Vol. 3, Issue 3, pp: (101-115). Available at: www.noveltyjournals.com.

4. Health Service Executive. Guideline on Management of Postpartum Hemorrhage, home birth service, revision .2016; No. 1 .

5. Kaur, M; Sagar, N; and Mamta. Knowledge and practices regarding antenatal assessment among obstetric nurses. International Journal of Development Research. 2016; 6(2): 6880-6883. Available online at http://www.journalij. Com.

6. Kumar, N; Kant, N; and Samar, S. Role of Simulation-based teaching in Management of Postpartum Hemorrhage amongst Postgraduate Students of Department of Obstetrics and Gynecology. A Prospective Study Future of Medical Education Journal. 2016; (1):31-35.

7. Mohammed, H; \& EL Sayed, H. Knowledge and attitude of maternity nurses regarding cord blood collection and stem cells: An educational intervention. Journal of Nursing Education and Practice. 2015;5(4): 58-69.

8. Motanya, S. Implementing an evidence-based educational module on nurses' role on management of postpartum hemorrhage, Doctoral thesis, College of Health Sciences, Walden University. 2015

9. World Health Organization. Maternal mortality. Global Health Observatory (GHO) data. Retrieved from http://www.who.int/gho/maternal_ health/ mortality/maternal_mortality text/en/29.04.16 WHO, UNICEF, UNFPA, World Bank .2016

10. World Health Organization. Maternal mortality ratio (per 100000 live births).2017; Retrieved from http://www.who.int/healthinfo/statistics/ indmaternalmortality/en/

11. WHO. WHO recommendations Uterotonics for the prevention of postpartum haemorrhage. (OVoge, 1 Joshua. Oladapo, Ed.). Geneva swazland: World Health Organization. 2018. 